\title{
Neurocognitive Functioning in Children with Developmental Dyslexia and Attention- Deficit/Hyperactivity Disorder: Multiple Deficits and Diagnostic Accuracy
}

Running head: Neurocognitive functioning in DD and ADHD

Moura, O., Pereira, M., Alfaiate, C., Fernandes, E., Fernandes, B., Nogueira, S., . . Simões, M. R. (2017). Neurocognitive functioning in children with developmental dyslexia and attentiondeficit/hyperactivity disorder: Multiple deficits and diagnostic accuracy. Journal of Clinical and Experimental Neuropsychology, 39(3), 296-312. doi:10.1080/13803395.2016.1225007

Octávio Moura ${ }^{1,2}$, Marcelino Pereira ${ }^{1,2,3}$, Cláudia Alfaiate ${ }^{4}$, Eva Fernandes ${ }^{4}$, Boavida Fernandes ${ }^{4}$, Susana Nogueira ${ }^{4}$, Joana Moreno ${ }^{3}$ and Mário R. Simões ${ }^{1,2,3}$

${ }^{1}$ Psychological Assessment and Psychometrics Laboratory, Faculty of Psychology and Educational Sciences, University of Coimbra, Portugal

${ }^{2}$ Neurosciences, Neuropsychology and Cognitive Assessment group from the Cognitive and Behavioral Center for Research and Intervention (CINEICC), University of Coimbra, Portugal

${ }^{3}$ Faculty of Psychology and Educational Sciences, University of Coimbra, Portugal

${ }^{4}$ Coimbra University Hospitals - Pediatric Hospital, Portugal 


\title{
Neurocognitive Functioning in Children with Developmental Dyslexia and Attention- Deficit/Hyperactivity Disorder: Multiple Deficits and Diagnostic Accuracy
}

\begin{abstract}
Introduction: This study aimed to investigate the neurocognitive functioning of children with Developmental Dyslexia (DD) and Attention-Deficit/Hyperactivity Disorder (ADHD).

Method: Four groups of children between the ages of 8 and 10 years participated in the study: typically developing children (TDC; $N=34)$, children with DD-only $(N=32)$, children with ADHD-only $(N=32)$ and children with DD+ADHD $(N=18)$. Results: Children with DD and ADHD exhibited significant weaknesses on almost all neurocognitive measures compared with TDC. Large effect sizes were observed for naming speed and phonological awareness. The comorbid group showed deficits consistent with both DD and ADHD without additional impairments. Results from binary logistic regression and ROC curve analyses suggested that some neurocognitive measures revealed an adequate sensitivity for the clinical diagnosis of both neurodevelopmental disorders. Specifically, naming speed and phonological awareness were the strongest predictors to correctly discriminate both disorders. Conclusions: Taken together, the results lend support to the multiple cognitive deficit hypothesis showing a considerable overlap of neurocognitive deficits between both disorders.
\end{abstract}

Keywords: developmental dyslexia, attention-deficit/hyperactivity disorder (ADHD), neurocognitive functioning, diagnostic accuracy, multiple cognitive deficit hypothesis.

\section{Introduction}

Developmental Dyslexia (DD) and Attention-Deficit/Hyperactivity Disorder (ADHD) are two of the most common neurodevelopmental disorders, and each of them occurs in approximately 5\% of the population (American Psychiatric Association, 2000, 2013). These 
disorders co-occur more frequently than expected by chance in both population- and clinicalbased samples ( $25 \%$ to $40 \%$ of individuals with ADHD meet criteria for DD, $15 \%$ to $40 \%$ of individuals with DD meet criteria for ADHD, and the comorbidity rate between ADHD and learning disabilities is 45.1\%) (DuPaul, Gormley, \& Laracy, 2013; Willcutt, Pennington,

Olson, Chhabildas, \& Hulslander, 2005), suggesting that this comorbidity is not a consequence of selection bias.

Traditionally, neuropsychological models of neurodevelopmental disorders have proposed that a single primary neurocognitive deficit was sufficient to explain all of the symptoms observed for a disorder (e.g., Barkley, 1997; Ramus et al., 2003). However, findings from several studies have challenged the validity of the single cognitive deficit model (for a review, see Germanò, Gagliano, \& Curatolo, 2010). In the attempt to explain the cause of comorbidity and the presence of a considerable overlap of neurocognitive deficits between neurodevelopmental disorders, some researchers have suggested a multiple cognitive deficit model for understanding "complex" neurodevelopmental disorders (McGrath et al., 2011; Pennington, 2006; Pennington et al., 2012; Willcutt et al., 2010). Thus, in the subsequent sections, we summarize current knowledge regarding the neurocognitive phenotype of children with DD, ADHD and with both disorders (DD+ADHD).

\section{Neurocognitive Deficits in Children with DD}

DD can be conceptualized as a specific learning disorder that is neurobiological in origin and characterized by problems with accurate or fluent word recognition, poor decoding and poor spelling abilities. These traits typically result from a phonological deficit and are not better accounted for by intellectual disabilities, sensory impairments or inadequate educational instruction (American Psychiatric Association, 2013; Lyon, Shaywitz, \& Shaywitz, 2003). Deficits in phonological awareness and naming speed [which is typically measured by 'rapid automatized naming' (RAN) tasks] relative to chronological age-matched 
controls and/or reading level-matched controls have been consistently found in children with DD in transparent (Tobia \& Marzocchi, 2014), intermediate (Boets et al., 2010; Moura, Moreno, Pereira, \& Simões, 2015) and opaque orthographies (Caravolas, Volín, \& Hulme, 2005; Landerl et al., 2013). Phonological awareness is the most relevant predictor of reading decoding in children with DD and typically developing children (TDC; although its weight varies as a function of script transparency), whereas naming speed is more related to reading fluency (Ziegler et al., 2010).

Although a large number of studies have consistently found that the phonological domain is the most relevant endophenotype of DD (Fletcher, 2009; Ramus, Marshall, Rosen, \& van der Lely, 2013; Vellutino, Fletcher, Snowling, \& Scanlon, 2004), children with DD also have weaknesses in several other neurocognitive domains. For example, children with DD had significant difficulties in the phonological loop and the central executive components (Moura, Simões, \& Pereira, 2015b; Swanson, Zheng, \& Jerman, 2009) of Baddeley's working memory (WM) model (Baddeley, 2012). Mixed results were found in the visuospatial sketchpad component. Although most studies have not shown visuospatial short-term memory deficits in individuals with DD (Bacon, Parmentier, \& Barr, 2013; Kibby \& Cohen, 2008), others have suggested the presence of significant differences (Menghini, Finzi, Carlesimo, \& Vicari, 2011). Moreover, the WM plays an important role in the development of reading skills. Specifically, the phonological loop and the central executive components predicted variance in reading decoding, reading fluency and reading comprehension (Moura, Simões, et al., 2015b; Nevo \& Breznitz, 2011; Swanson \& Jerman, 2007; Swanson et al., 2009) even after controlling for other neurocognitive variables (phonological awareness and naming speed) which are known to be strong predictors of reading (Boets et al., 2010; Ziegler et al., 2010).

In comparison to TDC, children with DD revealed difficulties in a range of other specific executive functions (EF) that include shifting (Marzocchi et al., 2008), processing speed (Shanahan et al., 2006), inhibition (Willcutt, Pennington, et al., 2005), verbal fluency 
(Varvara, Varuzza, Sorrentino, Vicari, \& Menghini, 2014), among others. Group differences on several of these EF tasks remained significant after general intellectual ability was statistically controlled (Moura, Simões, \& Pereira, 2015a; Willcutt, Pennington, et al., 2005). Taken together, these findings from the literature provide evidence of the multiple cognitive deficit hypothesis.

\section{Neurocognitive Deficits in Children with ADHD}

ADHD has been conceptualized as resulting from dysfunction in the prefrontal-striatal circuitry that underpins deficits in EF (Castellanos \& Proal, 2012). Numerous studies demonstrate that children with ADHD performed poorly on measures of processing speed (Shanahan et al., 2006; Willcutt, Pennington, et al., 2005), inhibition (Barkley, 1997), WM (Alloway \& Cockcroft, 2014), verbal fluency (Takács, Kóbor, Tárnok, \& Csépe, 2014), and shifting (Roberts, Martel, \& Nigg, 2013), among others. Willcutt, Doyle, et al. (2005) conducted a meta-analytic review of 83 studies and found that groups with ADHD exhibited significant impairments on all EF tasks, in particular on measures of response inhibition, vigilance, WM and planning. Weaknesses in EF tasks were significant in both clinic-referred and community samples and were not explained by group differences in intelligence, academic achievement or symptoms of other disorders. Similarly, Kasper, Alderson and Hudec's (2012) meta-analytic review of 45 studies of WM performance in children with ADHD found statistically significant differences with large effect sizes relative to TDC in both verbal and visuospatial short-term memory measures.

In contrast, some researchers have argued that the efficacy (sensitivity) of EF in the diagnosis of ADHD is limited (Wasserman \& Wasserman, 2012) given the heterogenic nature of this disorder (Duff \& Sulla, 2014). Wåhlstedt, Thorell and Bohlin (2008) have found that $26 \%$ of the children with ADHD do not score in the clinically significant impairment range in any of the EF measures, $40 \%$ had only a single impairment and $34 \%$ had multiple 
impairments. Similarly, Nigg, Willcutt, Doyle and Sonuga-Barke (2004) also found that 18\% to $27 \%$ of individuals with ADHD do not show impairments in any of the EF measures and only $4 \%$ to $13 \%$ show significant impairments in five or more EF measures. In addition, Sergeant, Geurts and Oosterlaan (2002) conducted a meta-analytic study and observed that although individuals with ADHD have significant impairments in some EF, the pattern of these deficits was not consistent between studies (that is, those who do have EF deficits vary in which one(s) they have). On the other hand, impairments in EF are not specific to ADHD, children with other disorders (e.g., DD, dyscalculia, oppositional defiant disorder, conduct disorder, among others) also demonstrated significant deficits in some EF (for a review, see Sergeant et al., 2002; Wasserman \& Wasserman, 2012).

In addition to the well-documented relation between EF and ADHD symptoms, other studies have suggested that children with ADHD also exhibit weakness in other neurocognitive measures, which is consistent with the multiple cognitive deficit hypothesis. Although various studies did not find phonological processing deficits in children with ADHD (Gooch, Snowling, \& Hulme, 2011; Willcutt et al., 2001), others have demonstrated that phonological awareness and naming speed deficits are not limited to DD and are also observed in children with ADHD (de Jong, Licht, Sergeant, \& Oosterlaan, 2011; Willcutt et al., 2010). Children with ADHD are also slower or less accurate than TDC on measures of complex sentence comprehension (Wassenberg et al., 2010), lexical and/or sublexical route processing (de Jong et al., 2011; Willcutt, Pennington, et al., 2005), textual organization, spelling and punctuation errors (Mathers, 2006).

\section{Neurocognitive Deficits with the Comorbid Group (DD+ADHD)}

Several competing hypotheses have been proposed to understand the neurocognitive correlates of comorbid phenotypes (for a review, see Germanò et al., 2010; Willcutt, 
Pennington, et al., 2005). Next, we provide a brief description of the most plausible competing hypotheses to explain comorbidity between DD and ADHD.

The phenocopy hypothesis postulates that DD may cause the symptoms of ADHD (e.g., inattentiveness or hyperactivity in the classroom) as a consequence of frustrations elicited by difficulties with reading. Consequently, the comorbid group exhibits the neurocognitive deficits of DD only and the behavioral characteristics of both disorders. In the first study that used a full 2 (DD vs. non-DD) x 2 (ADHD vs. non-ADHD) design, Pennington, Groisser and Welsh (1993) found that the DD-only group was significantly impaired on phonological processing but performed normally on EF measures, whereas the ADHD-only group showed an opposite profile (double dissociation). The comorbid group profile was statistically indistinguishable from the DD-only group, supporting the phenocopy hypothesis. The double dissociation hypothesis predicts that DD and ADHD are associated with two opposite profiles of impairment in two different neurocognitive domains, whereas the comorbid group showed an additive combination of deficits on both domains. Willcutt et al. (2001) also used a 2 x 2 design and found that children with ADHD were associated with inhibition deficits, children with DD were associated with phonological awareness and verbal WM deficits, and the $\mathrm{DD}+\mathrm{ADHD}$ group was most impaired on virtually all measures. The cognitive subtype hypothesis suggests that the neurocognitive deficits of the comorbid group are different from the simple additive combination of the deficits associated with DD and ADHD alone. That is, the DD+ADHD group constitutes a third disorder as a consequence of additional neurocognitive weakness, forming a unique cognitive subtype that is more clinically impaired. Rucklidge and Tannock (2002) observed that the comorbid group was significantly slower than the DD-only and ADHD-only groups on measures of naming speed and reaction times, providing some support for this hypothesis. Some studies provided evidence about the presence of a considerable overlap of neurocognitive deficits between DD and ADHD (multiple deficit hypothesis). For example, Willcutt et al. $(2010 ; 2005)$ and Shanahan et al. 
(2006) found that children with DD or ADHD exhibited significant weakness on most neurocognitive measures and that the comorbid group was at least as impaired as the DD-only and ADHD-only groups.

That is, the multiple cognitive deficit model hypothesize that neurodevelopmental disorders are heterogeneous conditions which arise from the additive and interactive effects of multiple genetic and environmental risk factors leading to weaknesses in multiple neurocognitive domains (McGrath et al., 2011; Pennington, 2006; Pennington et al., 2012; Willcutt et al., 2010). Thus, this study aimed to investigate the neurocognitive functioning of children with DD and/or ADHD. It extended previous research by analyzing the presence of multiple (vs. single) neurocognitive deficits between children with DD-only, ADHD-only and $\mathrm{DD}+\mathrm{ADHD}$; and testing the diagnostic accuracy of these measures to discriminate between participants. Based on the existing literature, we hypothesized that: (i) children with DD and/or ADHD would have significant deficits in almost all neurocognitive measures compared with TDC (Duff \& Sulla, 2014; Moura, Simões, et al., 2015a; Pennington et al., 2012); (ii) children with DD and ADHD would share weaknesses on almost all neurocognitive measures (Willcutt, Pennington, et al., 2005), the exceptions would be the phonological awareness [more impaired in DD (De Groot, Van den Bos, Van der Meulen, \& Minnaert, 2015)] and the visuospatial short-term memory [more impaired in ADHD (Gooch et al., 2011)]; (iii) the comorbid group would have deficits consistent with both DD-only and ADHD-only without additional impairments (Shanahan et al., 2006; Willcutt, Pennington, et al., 2005); (iv) the neurocognitive measures would be accurate tasks for distinguished children with DD or ADHD from TDC (Bloch et al., 2012; Landerl et al., 2013).

This study makes two important contributions to the literature. First, the large body of research about the presence of neurocognitive deficits in children with DD and ADHD has been conducted in English-speaking samples [opaque orthography; i.e., containing many inconsistent grapheme-phoneme correspondence rules; for a review, see Seymour, Aro, and 
Erskine (2003)], although it is well known that the level of orthographic consistency may influence how DD is manifested (Landerl et al., 2013). The present study is the first to have been conducted in a Portuguese-speaking sample (intermediate orthography; i.e., containing less inconsistent grapheme-phoneme correspondence rules; for additional information about the characteristics of the European Portuguese orthography, see: Albuquerque (2012), Moura, Moreno, et al. (2015) and Sucena, Castro, and Seymour (2009)]. Investigating the presence of neurocognitive weakness across languages is important in order to help researchers to understand what factors are universal and which are orthography-specific factors. Second, and to the best of our knowledge, only one study that examined the presence of multiple neurocognitive deficits in children with DD and ADHD has analyzed the diagnostic accuracy of neurocognitive measures for discriminating both neurodevelopmental disorders (Willcutt et al., 2010). Investigating the sensitivity and specificity of the neurocognitive measures for the diagnosis of DD and ADHD is relevant in order to explore the clinical utility of these measures.

\section{Method}

\section{Participants}

The participants were 116 Portuguese children (69\% were male) between the ages of 8 and 10 years $(M=8.79, S D=0.73)$ and were in second to fifth grade in school. Four groups of children participated in the study: TDC, children with DD-only, children with ADHD-only and children with DD+ADHD. The TDC group comprised 34 children that did not meet the criteria for $\mathrm{DD}$ or $\mathrm{ADHD}$ diagnosis; $61.8 \%$ were male, with a mean age of 9.03 years $(S D=$ 0.67). The DD-only group included 32 children $(65.6 \%$ were male) with a mean age of 9.00 years $(S D=0.80)$. The ADHD-only group comprised 32 children $(75 \%$ were male $)$ with a mean age of 8.25 years $(S D=0.44)$. In the $\mathrm{DD}+\mathrm{ADHD}$ group $(N=18), 77.8 \%$ were male, with a mean age of 8.94 years $(S D=0.64)$. Groups did not differ in gender $\chi^{2}(3)=2.188, p=$ 
.534 , but statistically significant differences were found for age $\chi^{2}(6)=30.192, p<.001$. The influence of age on the neurocognitive measures was controlled by converting raw scores to age-scaled scores. The higher number of boys than girls is consistent with the hypothesis that the prevalence of males with DD and/or ADHD is significantly higher in referred or clinical samples than in population samples (Hawke, Olson, Willcut, Wadsworth, \& DeFries, 2009; Soendergaard et al., 2014).

Criteria for inclusion and procedures. For the four groups, only children who met the following criteria were included in the study: (i) WISC-III Full Scale IQ $\geq 85$; (ii) native speakers of European Portuguese; (iii) absence of a visual, hearing, or motor handicap; (iv) never diagnosed with a language impairment; emotional disturbance; developmental dyscalculia; disruptive, impulse-control and conduct disorders; neurological impairment or other psychiatric disorder. All participants attended regular classes in public and private schools.

TDC. The TDC group was recruited through contact with teachers, parents, and other participants using a snowball sampling strategy. Children with learning difficulties, grade retention and special educational needs were excluded. The Conners Rating Scale - Revised (Conners, 1997; Portuguese version: Rodrigues, 2007) or the Rutter Children Behaviour Questionnaire (Portuguese version: Pereira et al., 2008; Rutter, 1967, 1970) were completed by parents and teachers of TDC and children with DD-only to exclude children with ADHD symptoms or behavior problems (only children with both parents' and teachers' ratings below the clinical threshold were included). Additionally, only TDC who scored within the normal range (percentile $\geq 40$ ) on both reading fluency and reading accuracy measures ("O Rei"; Carvalho \& Pereira, 2009) administered during the testing session participated in the study.

DD-only. Children with DD (DD-only and DD+ADHD) were recruited for participation through contact with psychologists, special education teachers, physicians and other educational or clinical professionals (e.g., teachers and speech therapists). For the DD-only 
group, in addition to the parents' and teachers' rating scales described above, only children who had previously been diagnosed with DD by a psychologist, child psychiatrist, developmental pediatrician or child neurologist and had received a score $\leq 15^{\text {th }}$ percentile $(<-$ $1 S D$ ) on both reading fluency and reading accuracy measures ("O Rei"; Carvalho \& Pereira, 2009) administered during the testing session, were included. These cut-off criteria are in accordance with the Diagnostic and Statistical Manual of Mental Disorders (DSM) $-5^{\text {th }}$ edition (American Psychiatric Association, 2013) and are similar (and in some cases stricter than) the inclusion criteria used by other studies (e.g., Bental \& Tirosh, 2007; Gooch et al., 2011).

ADHD-only. Children with ADHD-only were recruited from the Coimbra University Hospitals - Pediatric Hospital, Portugal. Diagnosis of ADHD-only was confirmed by a comprehensive clinical diagnostic assessment made by two qualified neurodevelopmental pediatricians. The assessments were based on a clinical evaluation during an interview session using the DSM - $4^{\text {th }}$ edition (American Psychiatric Association, 2000) criteria, both parent and teacher ratings of at least $1.5 S D(\mathrm{~T}$-score $\geq 65)$ above the mean on the ADHD Index of the Conners Rating Scale - Revised. In the ADHD-only group, $25 \%$ of the children met the criteria for ADHD predominantly inattentive subtype, $12.5 \%$ for ADHD predominantly hyperactive-impulsive subtype and $62.5 \%$ for ADHD combined subtype. Children with learning difficulties and grade retention were excluded.

$\boldsymbol{D D}+\boldsymbol{A D H D}$. Children with DD+ADHD met the following criteria: (i) a previous comorbid diagnosis of DD and ADHD; (ii) a score $\leq 15^{\text {th }}$ percentile on both reading fluency and reading accuracy measures (“O Rei”) administered during the testing session; and (iii) both parent and teacher ratings of at least $1.5 S D$ (T-score $\geq 65)$ above the mean on the ADHD Index of the Conners Rating Scale - Revised. In the DD+ADHD group, $38.9 \%$ of the children met the criteria for ADHD predominantly inattentive subtype, 11.1\% for ADHD predominantly hyperactive-impulsive subtype and 50\% for ADHD combined subtype. No 
statistically significant differences were found in ADHD subtypes between ADHD-only and $\mathrm{DD}+\mathrm{ADHD}$ groups, $\chi^{2}(2)=1.070, p=.586$.

All children with ADHD-only and 39\% $(n=7)$ of children with DD+ADHD were not yet receiving stimulants (i.e., methylphenidate) because the neurocognitive measures were administered before the stimulant treatment. For the remaining $61 \%(n=11)$ of the children with DD+ADHD, as suggested by Alloway and Cockcroft (2014), they ceased taking their medication 24 hours prior to testing in order to ensure assessments were uninfluenced by medication. All of the neurocognitive measures were individually administered in a fixed order. The administration of the neurocognitive measures was made by psychologists trained and experienced in neuropsychological assessment. Informed parental consent and child assent was obtained for each evaluation.

\section{Measures}

Intellectual ability. The Portuguese version of the WISC-III (Wechsler, 2003) was administered to measure general intellectual ability. We used the General Ability Index (GAI; $M=100$ and $S D=15)$, rather than Full Scale IQ, because it excludes subtests that are related to executive functioning (processing speed and WM). That is, GAI is a composite score, which is derived from the four Verbal Comprehension Index subtests and the four Perceptual Organization Index subtests. As suggested by Prifitera, Weiss and Saklofske (1998), in some special educational cases (e.g., children with learning disability and ADHD), the GAI may be a slightly higher estimate of overall intellectual ability than the Full Scale IQ.

Phonological awareness. The Phonological Awareness subtest from the Coimbra Neuropsychological Assessment Battery ${ }^{1}$ (BANC; Simões et al., 2016, in press) comprises

\footnotetext{
${ }^{1}$ The BANC (Simões et al., 2016, in press) is a comprehensive assessment instrument tapping different functions of a child's neuropsychological development, which included 16 subtests organized in six main domains:
} 
two tasks. In the Deletion task (20 items), the child was asked to delete a particular phoneme on familiar words (e.g., item 1: say sopa [sope] (soup) without the $s$ [s]). In the Substitution task (20 items), the child was asked to replace one or more phonemes for other(s) phoneme(s) on familiar words (e.g., item 1: say judo [3udu] but replace the $j$ [3] to $x$ [S]). For both tasks, the raw scores were converted to scaled scores $(M=10, S D=3)$ based on age-specific norms.

Naming speed. The Naming Speed subtest from the BANC comprises two tasks. In the RAN task, the child was asked to name 50 visual stimuli (numbers 2, 4, 6, 7 and 9) as quickly as possible, which were randomly displayed on a card in a 10x5 matrix. In the Rapid Alternating Stimulus (RAS) task, the child was asked to name 50 visual stimuli (circle, rectangle, square and triangle which are colored yellow, red, black and green) as quickly as possible, which were randomly displayed on a card in a 10x5 matrix. For both tasks, the raw scores were converted to age-scaled scores.

Processing speed. The Coding and Symbol Search subtests from the WISC-III Processing Speed Index were used to measure processing speed. The Coding subtest requires that the child rapidly copy (in two minutes) nine types of symbols, each paired with a number, using a key provided at the top of the page. The Symbol Search subtest requires that the child match a specific symbol to an identical target that is displayed among several distracter stimuli (in two minutes). Age-scaled scores from the Portuguese version of the WISC-III were used for both tasks.

Verbal WM. The Digit Span and Arithmetic subtests from the WISC-III and the Word Learning List subtest from the BANC were selected to assess verbal WM. The Digit Span subtest required that the child correctly recall a series of two to nine digits in the order in

\footnotetext{
Memory, Language, Attention and Executive Functions, Motor Function, Laterality, and Orientation. The BANC was normed on a representative and stratified sample of 1,104 Portuguese children (aged 5 to 15 years) and revealed adequate psychometric properties (Moura et al., submitted).
} 
which they were presented (forward task) and a series of two to eight digits in the reverse order (backward task). The Arithmetic subtest required that the child solve a series of verbally presented arithmetic problems without using paper. To solve each problem correctly, the child must retain and manipulate in memory the information provided by the examiner. In the Word Learning List subtest from the BANC, a list of 15 unrelated words was read to the child four consecutive times. Following each trial, the child was asked to recall as many words as possible (total learning). A new list with 15 words was then presented and recalled once (interference recall). Then, the child was asked to recall the first word list immediately (shortdelay recall) and after a 20- to 30-minute delay (long-delay recall). Finally, a list of 45 words was presented, and the child was asked to identify the 15 first-list words (recognition). Because the purpose of the Word Learning List was to measure verbal WM, only the shortdelay recall score was considered in the subsequent analyses. For the three subtests, the raw scores were converted to age-scaled scores. These tasks are conventional measures used to assess verbal WM (Bora et al., 2008; Willcutt, Pennington, et al., 2005).

Visuospatial short-term memory. The Corsi Blocks and the Rey Complex Figure subtests from the BANC were administered to measure visuospatial short-term memory. The Corsi Blocks subtest consists of nine blocks nailed onto a board at random positions. The child was asked to reproduce the sequence (from two to nine blocks) by touching the blocks in the same order as the examiner. In the Rey Complex Figure, the child was instructed to copy the complex figure as accurately as possible and then reproduce it from memory 3 minutes later (immediate recall) and 20 to 30 minutes later. Because the purpose of the Rey Complex Figure was to measure visuospatial short-term memory, only the immediate recall score was considered. For both subtests, the raw scores were converted to age-scaled scores. These two tasks are widely used to assess visuospatial short-term memory (Smith-Spark \& Fisk, 2007; Wisniewski, Wendling, Manning, \& Steinhoff, 2012). 
Shifting. The Trail-B subtest from the BANC was administered to examine participants' shifting ability. The Trail-B subtest requires the child to draw a line connecting 25 circles containing numbers or letters randomly distributed on a sheet of paper, alternating between numbers and letters (1, A, 2, B, etc.). The raw score represents the amount of time (in seconds) taken to complete the task. The raw scores were converted to age-scaled scores. In order to obtain a "purer" measure of shifting (Drane, Yuspeh, Huthwaite, \& Klingler, 2002; Kortte, Horner, \& Windham, 2002), a standardized residual score was created by regressing Trail-B scores onto Trail-A scores [this subtest requires the child to draw a line sequentially connecting 25 encircled numbers (1 through 25)].

Verbal fluency. The Verbal Fluency subtest from the BANC comprises three semantic (Animals, Names, and Food) and three phonemic (letters P, M, and R) tasks. For each of the semantic and phonemic tasks, the child was asked to generate as many words as possible within a time constraint of 60 seconds. The raw score was the total number of correct words (different forms of the same word were excluded) generated within the time limit for the three semantic and the three phonemic tasks. The raw scores were converted to age-scaled scores.

\section{Statistical Analyses}

The statistical analyses were performed using IBM SPSS Statistics 20. To examine the presence of neurocognitive deficits between the groups, a $2 \times 2$ factorial univariate analysis of variance (ANOVA) was performed for each neurocognitive measure with the DD group (DD vs. non-DD) and ADHD group (ADHD vs. non-ADHD) as fixed factors. Due to the number of statistical comparisons being conducted to analyze the performance of the four groups on the neurocognitive measures (Type I error), a $p<.01$ was adopted as the threshold for statistical significance, whereas $p$ values between .05 and .01 were identified as marginally significant. If the initial ANOVA revealed a significant main effect of DD or ADHD groups or a significant DD x ADHD interaction, planned post hoc comparisons were conducted 
among the four groups (TDC vs. DD-only vs. ADHD-only vs. DD+ADHD) with a Bonferroni adjustment for multiple comparisons.

To evaluate the contribution of each neurocognitive measure to accurately discriminate between TDC, children with DD-only and children ADHD-only, we carried out a binary logistic regression analysis. The sensitivity and specificity values of each neurocognitive domain and the statistical tests of individual predictors were analyzed. Additionally, a receiver operating characteristics (ROC) curve analysis was also performed. A ROC curve analysis systematically sweeps across all possible true-positive (sensitivity) and false-positive (1-specificity) values of a diagnostic test and calculates the area under the curve (AUC). The AUC is the average of the true-positive rate, taken uniformly over all possible false-positive rates that range between .5 (reflects a completely random classifier) and 1.0 (perfectly accurate because the sensitivity is 1.0 when the false-positive rate is .0$)$. The more accurately a task discriminates between groups, the higher is its AUC value. An AUC of .5 to .7 indicates poor discrimination, .7 to .8 indicates acceptable discrimination, .8 to .9 is excellent discrimination, and .9 to 1.0 indicates outstanding discrimination (Hosmer, Lemeshow, \& Sturdivant, 2013).

\section{Results}

\section{Group differences on general intellectual ability}

The Portuguese version of the WISC-III was administered to measure general intellectual ability. A 2 (DD vs. non-DD) x 2 (ADHD vs. non-ADHD) factorial univariate analysis of variance yielded a non-significant main effect for DD and ADHD groups and a non-significant DD x ADHD interaction in the WISC-III GAI score (see Table 1). Because non-significant group differences were found in the GAI score, in the subsequent group comparisons, the general intellectual ability was not statistically controlled. 


\section{Group differences on neurocognitive measures}

A 2 (DD vs. non-DD) x 2 (ADHD vs. non-ADHD) factorial ANOVA was performed for each individual neurocognitive measure and for each composite score (the composite score was created by computing the mean of the age-scaled scores of the subtests included in each neurocognitive domain, the exception was shifting because it only includes one subtest). The DD group had a significant main effect for all neurocognitive measures, except for phonemic verbal fluency and visuospatial short-term memory measures [i.e., children with DD (DD-only and DD+ADHD) differed significantly from children without DD (TDC and ADHD-only)]. Similarly, the ADHD group main effect was significant for most neurocognitive measures and composite scores [i.e., children with ADHD (ADHD-only and DD+ADHD) differed significantly from children without ADHD (TDC and DD-only)]. A significant DD x ADHD interaction was found for phonological awareness, naming speed, visuospatial short-term memory measures, suggesting that the performance of the comorbid group reflects interactive rather than additive effects of having both disorders (see Table 1).

Planned post hoc comparisons among the four groups revealed the presence of significant differences between the children with neurodevelopmental disorders and TDC on most neurocognitive measures. Compared to the ADHD-only group, children with DD-only revealed the most pronounced impairments in the Phonological Awareness (Deletion task) and Digit Span subtests. In contrast, the DD-only group outperformed the ADHD-only group in the Corsi Blocks. For the remaining subtests, both groups (DD-only and ADHD-only) revealed a very similar pattern of results. In general, the DD+ADHD group did not perform significantly lower than the DD-only and ADHD-only groups, suggesting that the comorbid group was at least as impaired as the other two neurodevelopmental disorders.

(Table 1 about here) 
Because of the possibility of Type II error when comparing groups and to obtain a more detailed analysis of the group differences, effect sizes (Cohen's $d$ ) were additionally computed for the composite scores (see Table 2). According to Cohen's (1988) criteria, $d$ effect sizes are considered to be large if exceeding 0.80 , moderate if at 0.50 and small if less than 0.20. As expected, the DD-only, ADHD-only and DD+ADHD groups differed substantially from TDC on most neurocognitive measures. The magnitude of differences between the DD-only group and ADHD-only group was moderate on measures of phonological awareness and verbal WM (in favor of ADHD-only) and on measures of visuospatial short-term memory (in favor of DD-only). For the remaining measures, the magnitude of differences was small. The DD+ADHD group had a small to moderate disadvantage over the DD-only and ADHD-only groups on almost all neurocognitive measures; and an advantage on measures of visuospatial short-term memory.

(Table 2 about here)

\section{Binary logistic regression analysis and ROC curve analysis}

Although the findings presented above report the presence of significant differences on most neurocognitive measures, it is not certain that these measures can successfully discriminate between groups. Therefore, a binary logistic regression analysis and a ROC curve analysis were performed to determine which neurocognitive measures independently contributed to distinguishing between TDC, children with DD-only and children with ADHDonly. These analyses were not conducted for children with DD+ADHD because the comorbid group only includes 18 children.

An individual binary logistic regression analysis was performed for each neurocognitive domain (see Table 3). As expected, the phonological awareness was the most reliable predictor of DD-only diagnosis (correctly classified $93.9 \%$ of the participants), followed by naming speed (correctly classified $84.8 \%$ of the participants) and verbal WM (correctly 
classified $80.7 \%$ of the participants). Phonological Awareness - Deletion was the most significant individual predictor with an odds ratio of $0.491\left(=e^{-.712}\right)$. For each 1-point increase in the Phonological Awareness - Deletion age-scaled score, the odds of being in the DD-only group decreased by $50.9 \%$. Similarly, the phonological awareness and the naming speed (correctly classified $81.8 \%$ of the participants) and verbal WM (correctly classified $77.3 \%$ of the participants) were the most reliable predictors of ADHD-only diagnosis. The Arithmetic subtest was the most significant individual predictor with an odds ratio of $0.574\left(=\mathrm{e}^{-.533}\right)$.

The results from the ROC curve analysis (see Table 3) confirmed that phonological awareness tasks were the most relevant measures for discriminating between TDC and children with DD-only, with an AUC value of .966 and .950, respectively (i.e., a randomly selected child with DD-only will have a lower score than a randomly selected child from the TDC group approximately $96.6 \%$ and $95.0 \%$ of the time, respectively). Naming speed and shifting revealed excellent discrimination $(.80<\mathrm{AUC}<.90)$, whereas the other measures had poor to acceptable diagnostic accuracy. For the ADHD-only group, five measures demonstrated excellent accuracy to correctly discriminate from TDC (RAN, RAS, Phonological Awareness - Deletion, Arithmetic and Phonological Awareness - Substitution) with $.80<$ AUC $<.90$. The remaining measures showed poor to acceptable discrimination.

Another ROC curve analysis was performed to examine the diagnostic accuracy of neurocognitive measures to correctly discriminate children with DD-only from children with ADHD-only (a binary logistic regression analysis was not performed because it did not make empirical sense). The AUC values ranged from .501 (Arithmetic) to .696 (Corsi Blocks), demonstrating poor discrimination.

(Table 3 about here)

\section{Discussion}


The purpose of the current study was to examine the presence of multiple (vs. single) neurocognitive deficits between children with DD and/or ADHD; and the diagnostic accuracy of the neurocognitive measures to correctly discriminate between participants.

\section{Neurocognitive functioning of children with DD}

As expected, children with DD (DD-only and DD+ADHD) revealed pronounced deficits on phonological awareness and naming speed measures. These findings provide further support for the hypothesis that the ability to perceive and manipulate the sounds of spoken words and the rapid access of phonological information stored in the mental lexicon were markedly impaired in children with DD (Boets et al., 2010; Caravolas et al., 2005; Moura, Moreno, et al., 2015).

Weaknesses in verbal WM but not visuospatial short-term memory were also observed in the DD groups (DD-only and DD+ADHD), which replicates other studies that used the same or similar measures (Bacon et al., 2013; Kibby \& Cohen, 2008). Almost all studies investigating verbal WM have documented reductions in the verbal span in children with DD, which can be caused by a deficient store mechanism, subvocal rehearsal mechanism or articulatory/speech rate (for a review, see Kibby, 2009). Verbal short-term memory is commonly included as a component of the phonological processing (Boets et al., 2010) that plays an important role in reading decoding, reading fluency, reading comprehension and spelling (Moura, Simões, et al., 2015b; Nevo \& Breznitz, 2011). Indeed, the temporary storage of material that has been read is dependent on verbal short-term memory, which takes into account the storage of items for later retrieval and the demands of the partial storage of information related to several levels of text processing (Swanson, 1999; Swanson et al., 2009).

Children with DD-only did not reveal deficits in the Coding and Symbol Search subtests but demonstrated weaknesses on other measures that are also related to processing speed, 
such as RAN and RAS. These findings suggest that children with DD-only may exhibit more deficits on measures that place greater demands on verbal abilities. Shanahan et al. (2006) performed a detailed study that examined the presence of processing speed deficits in children and adolescents with DD and ADHD using a wide range of speeded tasks, which included verbal (e.g., RAN tasks) and motor (e.g., Trail Making Test and WISC-R Coding) stimuli tasks. The results suggested that, compared with TDC, a general processing speed deficit exists in both disorders, but children with DD showed greater processing speed deficits than children with ADHD, particularly in tasks that include verbal stimuli. Moll and colleagues (2014) also found that children with DD revealed a significant impairment on a verbal processing speed task (RAN) compared to TDC and children with Dyscalculia, but nonsignificant differences were found for a nonverbal processing speed task.

\section{Neurocognitive functioning of children with ADHD}

Children with ADHD-only revealed the most significant weaknesses on naming speed, phonological awareness and visuospatial short-term memory measures. Although far less studied in children with ADHD, some studies have shown that naming speed deficits are also observed in ADHD and are not limited to DD (Arnett et al., 2012; de Jong et al., 2011). Recently, Bexkens, van den Wildenberg and Tijms (2015) hypothesized that, in addition to the involvement of phonological processes and processing speed, RAN also involves response inhibition. The significant DD x ADHD interaction and the magnitude of the effect sizes on naming speed measures provide evidence that naming speed deficits were not additive in the DD+ADHD group, suggesting that deficits were at least partially shared between DD and ADHD. On the other hand, the RAS task was the lowest subtest for both ADHD groups (ADHD-only and DD+ADHD). This measure was first developed by Wolf (1986) as a way to incorporate processes involved in shifting and attention in a rapid serial naming task. Thus, as the performance on the RAS is particularly dependent on processing speed, response 
inhibition, shifting and attention abilities, it is not surprising that RAS was the most difficult measure among children with ADHD. Interestingly, Whipple and Nelson (2015) found that the ADHD-only group performed significantly higher on measures of alphanumeric RAN (digits and letters) than non-alphanumeric RAN (colors and objects) tasks. They suggested that individuals with ADHD might experience particular difficulties with the rapid naming of colors and objects due to the semantic processing and executive functioning demands of these tasks.

Although phonological awareness in ADHD has not often been the object of research, there is some evidence of phonological awareness deficits in children with ADHD. Consistent with our findings, De Groot and colleagues (2015) and Willcutt et al. (2005) found that children with ADHD-only revealed significant difficulties on phonological awareness tasks compared to TDC, but they were less impaired than children with DD. Recently, Kóbor et al. (2015) also found that children with ADHD have marked impairments on phonological awareness, exhibiting the largest effect size among the neurocognitive measures administered. They hypothesized that children with ADHD show multiple deficits in information processing rather than a specific response inhibition impairment. On the other hand, the deletion and substitution of phonemes requires the ability to discriminate, store and manipulate phonemes, which imposes additional demands on WM. This is particularly true to the phoneme substitution task which, theoretically, involves a larger WM load than the deletion task (De Groot et al., 2015). Recent studies also revealed that phonological awareness can be significantly affected by inattention (Martinussen, Grimbos, \& Ferrari, 2014; Sims \& Lonigan, 2013). Indeed, approximately $88 \%$ of the children with ADHD met the criteria for predominantly inattentive or combined subtypes and manifested weakness in verbal WM, which might partially explain the poor performance on phonological awareness tasks. Another possible explanation is that some children with ADHD exhibit subclinical manifestations of 
DD even though they do not meet the full criteria for DD, and children with a history of learning difficulties were excluded from the ADHD-only group in the present study.

In contrast to the DD groups, children with ADHD-only performed poorly on the visuospatial short-term memory, which is consistent with previous studies (Alloway \& Cockcroft, 2014; Kibby \& Cohen, 2008; Martinussen, Hayden, Hogg-Johnson, \& Tannock, 2005). Future studies should explore the hypothesis that visuospatial short-term memory might be an important variable to differentiate these two disorders. In addition, our results also indicate that ADHD is associated with deficits on processing speed, verbal WM, shifting and verbal fluency, which confirms earlier findings (Takács et al., 2014; Willcutt, Pennington, et al., 2005).

\section{Neurocognitive functioning of the comorbid group}

As reported by previous studies (Kibby \& Cohen, 2008; Shanahan et al., 2006; Willcutt, Pennington, et al., 2005), the comorbid group exhibited significant weakness on almost all neurocognitive measures compared with TDC, but did not perform significantly lower than the DD-only and ADHD-only groups. Thus, of the competing hypotheses that have been proposed to understand comorbidity between DD and ADHD, our findings are most consistent with the multiple deficit hypothesis (Willcutt, Pennington, et al., 2005).

Another interesting research question was to understand whether the effects of each disorder on neurocognitive measures are additive (i.e., independent) or underadditive (i.e., interactive). The results showed a significant DD x ADHD interaction for phonological awareness, naming speed and visuospatial short-term memory, suggesting that the effects of having both disorders were not simply additive. That is, the mean difference of these measures in the comorbid group was less than the sum of the mean differences in the DD-only and ADHD-only groups. For the remaining measures a non-significant DD x ADHD interaction was found, which is consistent with the simple additive combinations of the 
deficits of the DD-only and ADHD-only groups. All these results seems to suggest that naming speed (and probably phonological awareness) is a shared neurocognitive risk measure that might explain the comorbidity between both disorders. Shanahan et al. (2006, p. 597) also found that naming speed tasks as well as other verbal and motor processing speed measures "causes or at least contributes to the development of both RD and ADHD and help explains their common comorbidity". Similarly, de Jong et al. (2011) suggested that DD and ADHD may be overlapping disorders that share deficits in naming speed, lexical and sublexical route processing.

\section{Diagnostic accuracy of the neurocognitive measures}

Whereas the presence of significant impairments on neurocognitive measures in children with DD and ADHD has been extensively reported in the literature, there has limited research utilizing binary logistic regression and ROC curve analyses. Obviously, the presence of a significant difference alone does not indicate that a test can discriminate among participants with sufficient accuracy for clinical use. Thus, our second main objective was to analyze the accuracy with which the neurocognitive measures under study discriminate children with DD, ADHD and TDC.

Similar to the Landerl et al. (2013) and Moura and colleagues (Moura, Moreno, et al., 2015; Moura, Simões, et al., 2015a) studies, our findings provide further support for the hypothesis that phonological awareness is the most reliable marker of DD, followed by naming speed, verbal WM and shifting measures. These results are convergent with the Pennington et al. (2012) study that found that the single deficit model of DD has a more limited clinical utility than the multiple deficit model. For ADHD, more conservative diagnostic accuracy rates were obtained, probably due to the heterogeneity of this disorder (Koziol \& Budding, 2012; Wasserman \& Wasserman, 2012). A part of this heterogeneity may be related to the ADHD subtypes. Some studies have found that ADHD subtypes show 
distinctive patterns of neurocognitive weaknesses, age of onset, sex ratios, comorbidity, diagnostic instability, and academic and social impairment (Booth, Carlson, \& Tucker, 2007; Milich, Balentine, \& Lynam, 2001; Valo \& Tannock, 2010). Among the subtests included in the neurocognitive battery administered to participants, the RAN, RAS, Arithmetic and Phoneme Awareness were the most relevant subtests to correctly discriminate between children with ADHD and TDC. As we discussed earlier, while for the first three subtests there is evidence in the literature that supports the weakness of individuals with ADHD on these neurocognitive measures (de Jong et al., 2011; Willcutt, Pennington, et al., 2005), for phonological awareness mixed results have been obtained (Willcutt et al., 2010). Thus, future studies should explore whether phonological awareness deficits are another relevant neurocognitive phenotype of ADHD, a subclinical manifestation of DD or a specific characteristic of our sample.

These results suggest that some neurocognitive measures revealed an adequate sensitivity for the clinical diagnosis of these two neurodevelopmental disorders, particularly for the DD diagnosis. There is a growing consensus that neurocognitive measures are less sensitive in discriminating children with ADHD given the heterogenic nature of this disorder (for a review, see Duff \& Sulla, 2014). Indeed, several studies have demonstrated the lack of universality of EF deficits among individuals with ADHD (e.g., Sergeant et al., 2002; Willcutt, Doyle, et al., 2005). Moreover, the poor accuracy of the neurocognitive measures to discriminate between children with DD-only and ADHD-only are consistent with the hypothesis that these disorders share weaknesses on almost all neurocognitive measures. Obviously, the information obtained from neurocognitive assessment should only be a component of the clinical evaluation and decision-making process and needs to be viewed in the context of a more comprehensive assessment that includes other measures. For example, the diagnostic accuracy of ADHD is considerably better when measures of behavioral manifestations of EF (e.g., Behavior Rating Inventory of Executive Function) are included in 
the clinical evaluation (Toplak, Bucciarelli, Jain, \& Tannock, 2008), probably because they capture better the child's everyday behavioral manifestations (i.e., ecological validity) than do the performance-based measures (Barkley, 2012; Gioia, Isquith, Kenworthy, \& Barton, 2002).

\section{Limitations and Conclusions}

Notwithstanding the relevance of the present study, the results should be interpreted in light of some limitations. First, the majority of the neurocognitive measures were assessed only by only one or two tasks. Clearly the inclusion of more tasks per domain would have increased the construct validity and interpretability of the results. Second, the inclusion of other measures would also contribute to a better understanding of the neurocognitive functioning of children with DD and ADHD. The neurocognitive battery that was administered in the present study did not include measures of inhibition, planning, attention and visuospatial WM (the two visuospatial short-term memory tests administered in this study did not include mental manipulation); all of which have been shown to be associated with ADHD in previous studies (for a review, see Willcutt, Doyle, et al., 2005). Third, the DD+ADHD group only included 18 children, which limits the generalizability of the findings. Fourth, although the majority of the children with ADHD were not receiving stimulants, it would be a better baseline comparison if all children with ADHD were medication naïve. Fifth, our study did not analyze the neurocognitive functioning of the ADHD subtypes. It would be particularly interesting to examine the presence of specific neurocognitive weaknesses between ADHD subtypes and how they differ from children with DD.

Taken together, the results lend support to the multiple deficit hypothesis, showing a considerable overlap of neurocognitive deficits between both neurodevelopmental disorders. Indeed, children with DD and ADHD are both associated with weaknesses in multiple neurocognitive measures, and the comorbid group had deficits consistent with both DD and 
ADHD without additional impairments. Naming speed and phonological awareness were the strongest predictors to correctly discriminate both neurodevelopmental disorders.

\section{References}

Albuquerque, C. P. (2012). Rapid naming contributions to reading and writing acquisition of European Portuguese. Reading and Writing, 25(4), 775-797. doi: 10.1007/s11145-011-9299-6

Alloway, T. P., \& Cockcroft, K. (2014). Working memory in ADHD: A comparison of British and South African children. Journal of Attention Disorders, 18(4), 286-293. doi: 10.1177/1087054711417397 American Psychiatric Association. (2000). Diagnostic and statistical manual of mental disorders (4th - Text Revision ed.). Washington, DC: Author.

American Psychiatric Association. (2013). Diagnostic and statistical manual of mental disorders ( $5^{\text {th }}$ ed.). Washington, DC: Author.

Arnett, A. B., Pennington, B. F., Willcutt, E. G., Dmitrieva, J., Byrne, B., Samuelsson, S., \& Olson, R. K. (2012). A cross-lagged model of the development of ADHD inattention symptoms and rapid naming speed. Journal of Abnormal Child Psychology, 40(8), 1313-1326. doi: 10.1007/s10802-012-9644-5

Bacon, A. M., Parmentier, F. B. R., \& Barr, P. (2013). Visuospatial memory in dyslexia: Evidence for strategic deficits. Memory, 21(2), 189-209. doi: 10.1080/09658211.2012.718789

Baddeley, A. D. (2012). Working memory: Theories, models, and controversies. Annual Review of Psychology, 63(1), 1-29. doi: 10.1146/annurev-psych-120710-100422

Barkley, R. A. (1997). Behavioral inhibition, sustained attention, and executive functions: Constructing a unifying theory of ADHD. Psychological Bulletin, 121(1), 65-94. doi: 10.1037/0033-2909.121.1.65

Barkley, R. A. (2012). Executive functions: What they are, how they work, and why they evolved. New York: The Guilford Press.

Bental, B., \& Tirosh, E. (2007). The relationship between attention, executive functions and reading domain abilities in attention deficit hyperactivity disorder and reading disorder: A comparative study. Journal of Child Psychology and Psychiatry, 48(5), 455-463. doi: 10.1111/j.1469-7610.2006.01710.x

Bexkens, A., van den Wildenberg, W. P. M., \& Tijms, J. (2015). Rapid automatized naming in children with dyslexia: Is inhibitory control involved? Dyslexia, 21(3), 212-234. doi: 10.1002/dys.1487

Bloch, Y., Fixman, M., Maoz, H., Bloch, A. M., Levkovitz, Y., Ratzoni, G., . . Gal, G. (2012). Can computerized cognitive tests assist in the clinical diagnosis of attention-deficit hyperactivity disorder? 
The Journal of Neuropsychiatry and Clinical Neurosciences, 24(1), 111-114. doi:

10.1176/appi.neuropsych.11010014

Boets, B., de Smedt, B., Cleuren, L., Vandewalle, E., Wouters, J., \& Ghesquière, P. (2010). Towards a further characterization of phonological and literacy problems in Dutch-speaking children with dyslexia. British Journal of Developmental Psychology, 28(1), 5-31. doi: 10.1348/026151010x485223

Booth, J. E., Carlson, C. L., \& Tucker, D. M. (2007). Performance on a neurocognitive measure of alerting differentiates ADHD combined and inattentive subtypes: A preliminary report. Archives of Clinical Neuropsychology, 22(4), 423-432. doi: 10.1016/j.acn.2007.01.017

Bora, E., Vahip, S., Akdeniz, F., İlerisoy, H., Aldemir, E., \& Alkan, M. (2008). Executive and verbal working memory dysfunction in first-degree relatives of patients with bipolar disorder. Psychiatry Research, 161(3), 318-324. doi: 10.1016/j.psychres.2007.09.002

Caravolas, M., Volín, J., \& Hulme, C. (2005). Phoneme awareness is a key component of alphabetic literacy skills in consistent and inconsistent orthographies: Evidence from Czech and English children. Journal of Experimental Child Psychology, 92(2), 107-139. doi: 10.1016/j.jecp.2005.04.003

Carvalho, A., \& Pereira, M. (2009). O Rei: Um teste para avaliação da fluência e precisão da leitura no $1^{\circ}$ e $2^{\circ}$ ciclos do ensino básico [The King: Assessment test of the reading fluency and precision in the first and second cycles of elementary school]. Psychologica, 51, 283-305.

Castellanos, F. X., \& Proal, E. (2012). Large-scale brain systems in ADHD: beyond the prefrontal-striatal model. Trends in Cognitive Sciences, 16(1), 17-26. doi: 10.1016/j.tics.2011.11.007

Cohen, J. (1988). Statistical power analysis for the behavioral sciences (2 ${ }^{\text {nd }}$ ed.). New York: Academic Press.

Conners, C. K. (1997). Conners Rating Scales - Revised. Toronto: MHS.

De Groot, B. J. A., Van den Bos, K. P., Van der Meulen, B. F., \& Minnaert, A. E. M. G. (2015). Rapid naming and phonemic awareness in children with or without reading disabilities and/or ADHD. Journal of Learning Disabilities. doi: 10.1177/0022219415609186

de Jong, C. G. W., Licht, R., Sergeant, J. A., \& Oosterlaan, J. (2011). RD, ADHD, and their comorbidity from a dual route perspective. Child Neuropsychology, 18(5), 467-486. doi: 10.1080/09297049.2011.625354

Drane, D. L., Yuspeh, R. L., Huthwaite, J. S., \& Klingler, L. K. (2002). Demographic characteristics and normative observations for derived-trail making test indices. Neuropsychiatry, Neuropsychology, and Behavioral Neurology, 15(1), 39-43. 
Duff, C. T., \& Sulla, E. M. (2014). Measuring executive function in the differential diagnosis of attentiondeficit/hyperactivity disorder: Does it really tell us anything? Applied Neuropsychology: Child, 4(3), 188-196. doi: 10.1080/21622965.2013.848329

DuPaul, G. J., Gormley, M. J., \& Laracy, S. D. (2013). Comorbidity of LD and ADHD: Implications of DSM-5 for assessment and treatment. Journal of Learning Disabilities, 46(1), 43-51. doi: $10.1177 / 0022219412464351$

Fletcher, J. M. (2009). Dyslexia: The evolution of a scientific concept. Journal of the International Neuropsychological Society, 15(04), 501-508. doi: 10.1017/S1355617709090900

Germanò, E., Gagliano, A., \& Curatolo, P. (2010). Comorbidity of ADHD and dyslexia. Developmental Neuropsychology, 35(5), 475-493. doi: 10.1080/87565641.2010.494748

Gioia, G. A., Isquith, P. K., Kenworthy, L., \& Barton, R. M. (2002). Profiles of everyday executive function in acquired and developmental disorders. Child Neuropsychology, 8(2), 121-137. doi: 10.1076/chin.8.2.121.8727

Gooch, D., Snowling, M., \& Hulme, C. (2011). Time perception, phonological skills and executive function in children with dyslexia and/or ADHD symptoms. Journal of Child Psychology and Psychiatry, 52(2), 195-203. doi: 10.1111/j.1469-7610.2010.02312.x

Hawke, J. L., Olson, R. K., Willcut, E. G., Wadsworth, S. J., \& DeFries, J. C. (2009). Gender ratios for reading difficulties. Dyslexia, 15(3), 239-242. doi: 10.1002/dys.389

Hosmer, D. W., Lemeshow, S., \& Sturdivant, R. X. (2013). Applied logistic regression (3rd ed.). New York: Wiley.

Kasper, L. J., Alderson, R. M., \& Hudec, K. L. (2012). Moderators of working memory deficits in children with attention-deficit/hyperactivity disorder (ADHD): A meta-analytic review. Clinical Psychology Review, 32(7), 605-617. doi: 10.1016/j.cpr.2012.07.001

Kibby, M. Y. (2009). There are multiple contributors to the verbal short-term memory deficit in children with developmental reading disabilities. Child Neuropsychology, 15(5), 485-506. doi: $10.1080 / 09297040902748218$

Kibby, M. Y., \& Cohen, M. J. (2008). Memory functioning in children with reading disabilities and/or attention deficit/hyperactivity disorder: A clinical investigation of their working memory and long-term memory functioning. Child Neuropsychology, 14(6), 525-546. doi: 10.1080/09297040701821752 
Kóbor, A., Takács, Á., Bryce, D., Szűcs, D., Honbolygó, F., Nagy, P., \& Csépe, V. (2015). Children with ADHD show impairments in multiple stages of information processing in a Stroop Task: An ERP study. Developmental Neuropsychology, 40(6), 329-347. doi: 10.1080/87565641.2015.1086770

Kortte, K. B., Horner, M. D., \& Windham, W. K. (2002). The Trail Making Test, Part B: Cognitive flexibility or ability to maintain set? Applied Neuropsychology, 9(2), 106-109. doi: 10.1207/S15324826AN0902_5

Koziol, L. F., \& Budding, D. (2012). Requiem for a diagnosis: Attention-deficit hyperactivity disorder. Applied Neuropsychology: Child, 1(1), 2-5. doi: 10.1080/21622965.2012.665774

Landerl, K., Ramus, F., Moll, K., Lyytinen, H., Leppänen, P. H. T., Lohvansuu, K., . . Schulte-Körne, G. (2013). Predictors of developmental dyslexia in European orthographies with varying complexity. Journal of Child Psychology and Psychiatry, 54(6), 686-694. doi: 10.1111/jcpp.12029

Lyon, G. R., Shaywitz, S., \& Shaywitz, B. (2003). Defining dyslexia, comorbidity, teachers' knowledge of language and reading. Annals of Dyslexia, 53(1), 1-14. doi: 10.1007/s11881-003-0001-9

Martinussen, R., Grimbos, T., \& Ferrari, J. L. S. (2014). Word-level reading achievement and behavioral inattention: Exploring their overlap and relations with naming speed and phonemic awareness in a community sample of children. Archives of Clinical Neuropsychology, 29(7), 680-690. doi: 10.1093/arclin/acu040

Martinussen, R., Hayden, J., Hogg-Johnson, S., \& Tannock, R. (2005). A meta-analysis of working memory impairments in children with attention-deficit/hyperactivity disorder. Journal of the American Academy of Child \& Adolescent Psychiatry, 44(4), 377-384. doi: 10.1097/01.chi.0000153228.72591.73

Marzocchi, G. M., Oosterlaan, J., Zuddas, A., Cavolina, P., Geurts, H., Redigolo, D., . . Sergeant, J. A. (2008). Contrasting deficits on executive functions between ADHD and reading disabled children. Journal of Child Psychology and Psychiatry, 49(5), 543-552. doi: 10.1111/j.1469-7610.2007.01859.x

Mathers, M. E. (2006). Aspects of language in children with ADHD: Applying functional analyses to explore language use. Journal of Attention Disorders, 9(3), 523-533. doi: 10.1177/1087054705282437

McGrath, L. M., Pennington, B. F., Shanahan, M. A., Santerre-Lemmon, L. E., Barnard, H. D., Willcutt, E. G., . .. Olson, R. K. (2011). A multiple deficit model of reading disability and attention-deficit/hyperactivity disorder: Searching for shared cognitive deficits. Journal of Child Psychology and Psychiatry, 52(5), 547-557. doi: 10.1111/j.1469-7610.2010.02346.x

Menghini, D., Finzi, A., Carlesimo, G. A., \& Vicari, S. (2011). Working memory impairment in children with developmental dyslexia: Is it just a phonological deficity? Developmental Neuropsychology, 36(2), 199213. doi: $10.1080 / 87565641.2010 .549868$ 
Milich, R., Balentine, A. C., \& Lynam, D. R. (2001). ADHD combined type and ADHD predominantly inattentive type are distinct and unrelated disorders. Clinical Psychology: Science and Practice, 8(4), 463-488. doi: 10.1093/clipsy.8.4.463

Moll, K., Göbel, S. M., Gooch, D., Landerl, K., \& Snowling, M. J. (2014). Cognitive risk factors for specific learning disorder: Processing speed, temporal processing, and working memory. Journal of Learning Disabilities. doi: 10.1177/0022219414547221

Moura, O., Albuquerque, C. P., Pinho, M. S., Vilar, M., Lopes, A. F., Alberto, I., ... Simões, M. R. (submitted). Factor structure and measurement invariance of the Coimbra Neuropsychological Assessment Battery (BANC)

Moura, O., Moreno, J., Pereira, M., \& Simões, M. R. (2015). Developmental dyslexia and phonological processing in European Portuguese orthography. Dyslexia, 21(1), 60-79. doi: 10.1002/dys.1489

Moura, O., Simões, M. R., \& Pereira, M. (2015a). Executive functioning in children with developmental dyslexia. The Clinical Neuropsychologist, 28(S1), 20-41. doi: 10.1080/13854046.2014.964326

Moura, O., Simões, M. R., \& Pereira, M. (2015b). Working memory in Portuguese children with developmental dyslexia. Applied Neuropsychology: Child, 4(4), 237-248. doi: 10.1080/21622965.2014.885389

Nevo, E., \& Breznitz, Z. (2011). Assessment of working memory components at 6 years of age as predictors of reading achievements a year later. Journal of Experimental Child Psychology, 109(1), 73-90. doi: 10.1016/j.jecp.2010.09.010

Nigg, J. T., Willcutt, E. G., Doyle, A. E., \& Sonuga-Barke, E. J. S. (2004). Causal heterogeneity in attentiondeficit/hyperactivity disorder: Do we need neuropsychologically impaired subtypes? Biological Psychiatry, 57(11), 1224-1230. doi: 10.1016/j.biopsych.2004.08.025

Pennington, B. F. (2006). From single to multiple deficit models of developmental disorders. Cognition, 101(2), 385-413. doi: 10.1016/j.cognition.2006.04.008

Pennington, B. F., Groisser, D., \& Welsh, M. C. (1993). Contrasting cognitive deficits in attention deficit hyperactivity disorder versus reading disability. Developmental Psychology, 29(3), 511-523. doi: $10.1037 / 0012-1649.29 .3 .511$

Pennington, B. F., Santerre-Lemmon, L., Rosenberg, J., MacDonald, B., Boada, R., Friend, A., . . Olson, R. K. (2012). Individual prediction of dyslexia by single versus multiple deficit models. Journal of Abnormal Psychology, 121(1), 212-224. doi: 10.1037/a0025823 
Pereira, A. T., Maia, B. R., Marques, M., Bos, S. C., Soares, M. J., Gomes, A., . . Azevedo, M. H. P. (2008). Factor structure of the Rutter Teacher Questionnaire in Portuguese children. Revista Brasileira de Psiquiatria, 30(4), 322-327.

Prifitera, A., Weiss, L. G., \& Saklofske, D. H. (1998). The WISC-III in context. In A. Prifitera \& D. H. Saklofske (Eds.), WISC-III clinical use and interpretation: Scientist-practitioner perspectives (pp. 1-38). New York: Academic Press.

Ramus, F., Marshall, C. R., Rosen, S., \& van der Lely, H. K. J. (2013). Phonological deficits in specific language impairment and developmental dyslexia: Towards a multidimensional model. Brain, 136(2), 630-645. doi: 10.1093/brain/aws356

Ramus, F., Rosen, S., Dakin, S. C., Day, B. L., Castellote, J. M., White, S., \& Frith, U. (2003). Theories of developmental dyslexia: insights from a multiple case study of dyslexic adults. Brain, 126(4), 841-865. doi: 10.1093/brain/awg076

Roberts, B. A., Martel, M. M., \& Nigg, J. T. (2013). Are there executive dysfunction subtypes within ADHD? Journal of Attention Disorders. doi: 10.1177/1087054713510349

Rodrigues, A. R. (2007). Escalas Revistas de Conners: Formas reduzidas para pais e professores. In M. R. Simões, C. Machado, M. M. Gonçalves \& L. S. Almeida (Eds.), Avaliação Psicológica: Instrumentos validados para a população Portuguesa (Vol. III, pp. 203-227). Coimbra: Quarteto.

Rucklidge, J. J., \& Tannock, R. (2002). Neuropsychological profiles of adolescents with ADHD: Effects of reading difficulties and gender. Journal of Child Psychology and Psychiatry, 43(8), 988-1003. doi: $10.1111 / 1469-7610.00227$

Rutter, M. (1967). Children's Behavior Questionnaire for completion by teacher: Preliminary findings. Journal of Child Psychology and Psychiatry, 8(1), 1-11.

Rutter, M. (1970). Children's Behavior Questionnaire for completion by parents. In M. Rutter, J. Tizard \& K. Whitmore (Eds.), Education, health and behavior: Psychological and medical study of childhood development (pp. 412-421). New York: John Wiley \& Sons Inc.

Sergeant, J. A., Geurts, H., \& Oosterlaan, J. (2002). How specific is a deficit of executive functioning for Attention-Deficit/Hyperactivity Disorder? Behavioural Brain Research, 130(1-2), 3-28. doi: $10.1016 / \mathrm{S} 0166-4328(01) 00430-2$

Seymour, P. H. K., Aro, M., \& Erskine, J. M. (2003). Foundation literacy acquisition in European orthographies. British Journal of Psychology, 94(2), 143-174. doi: 10.1348/000712603321661859 
Shanahan, M. A., Pennington, B. F., Yerys, B. E., Scott, A., Boada, R., Willcutt, E. G., .. . DeFries, J. C. (2006). Processing speed deficits in attention deficit/hyperactivity disorder and reading disability. Journal of Abnormal Child Psychology, 34(5), 584-601. doi: 10.1007/s10802-006-9037-8

Simões, M. R., Albuquerque, C. P., Pinho, M. S., Pereira, M., Seabra-Santos, M. J., Alberto, I., ... Moura, O. (2016, in press). Bateria de Avaliação Neuropsicológica de Coimbra (BANC) [Coimbra Neuropsychological Assessment Battery]. Lisboa: Cegoc.

Sims, D. M., \& Lonigan, C. J. (2013). Inattention, hyperactivity, and emergent literacy: Different facets of inattention relate uniquely to preschoolers' reading-related skills. Journal of Clinical Child and Adolescent Psychology, 42(2), 208-219. doi: 10.1080/15374416.2012.738453

Smith-Spark, J. H., \& Fisk, J. E. (2007). Working memory functioning in developmental dyslexia. Memory, 15(1), 34-56. doi: 10.1080/09658210601043384

Soendergaard, H. M., Thomsen, P. H., Pedersen, E., Pedersen, P., Poulsen, A. E., Winther, L., .. . Soegaard, H. J. (2014). Associations of age, gender, and subtypes with ADHD symptoms and related comorbidity in a Danish sample of clinically referred adults. Journal of Attention Disorders. doi: $10.1177 / 1087054713517544$

Sucena, A., Castro, S. L., \& Seymour, P. (2009). Developmental dyslexia in an orthography of intermediate depth: The case of European Portuguese. Reading and Writing, 22(7), 791-810. doi: 10.1007/s11145008-9156-4

Swanson, H. L. (1999). Reading comprehension and working memory in learning-disabled readers: Is the phonological loop more important than the executive system? Journal of Experimental Child Psychology, 72(1), 1-31. doi: 10.1006/jecp.1998.2477

Swanson, H. L., \& Jerman, O. (2007). The influence of working memory on reading growth in subgroups of children with reading disabilities. Journal of Experimental Child Psychology, 96(4), 249-283. doi: 10.1016/j.jecp.2006.12.004

Swanson, H. L., Zheng, X., \& Jerman, O. (2009). Working memory, short-term memory, and reading disabilities: A selective meta-analysis of the literature. Journal of Learning Disabilities, 42(3), 260-287. doi: $10.1177 / 0022219409331958$

Takács, Á., Kóbor, A., Tárnok, Z., \& Csépe, V. (2014). Verbal fluency in children with ADHD: Strategy using and temporal properties. Child Neuropsychology, 20(4), 415-429. doi: 10.1080/09297049.2013.799645

Tobia, V., \& Marzocchi, G. M. (2014). Cognitive profiles of Italian children with developmental dyslexia. Reading Research Quarterly, 49(4), 437-452. doi: 10.1002/rrq.77 
Toplak, M. E., Bucciarelli, S. M., Jain, U., \& Tannock, R. (2008). Executive functions: Performance-based measures and the Behavior Rating Inventory of Executive Function (BRIEF) in adolescents with Attention Deficit/Hyperactivity Disorder (ADHD). Child Neuropsychology, 15(1), 53-72. doi: $10.1080 / 09297040802070929$

Valo, S., \& Tannock, R. (2010). Diagnostic instability of DSM-IV ADHD subtypes: Effects of informant source, instrumentation, and methods for combining symptom reports. Journal of Clinical Child \& Adolescent Psychology, 39(6), 749-760. doi: 10.1080/15374416.2010.517172

Varvara, P., Varuzza, C., Sorrentino, A. C. P., Vicari, S., \& Menghini, D. (2014). Executive functions in developmental dyslexia. Frontiers in Human Neuroscience, 8. doi: 10.3389/fnhum.2014.00120

Vellutino, F. R., Fletcher, J. M., Snowling, M. J., \& Scanlon, D. M. (2004). Specific reading disability (dyslexia): What have we learned in the past four decades? Journal of Child Psychology and Psychiatry, 45(1), 2-40. doi: 10.1046/j.0021-9630.2003.00305.x

Wåhlstedt, C., Thorell, L. B., \& Bohlin, G. (2008). Heterogeneity in ADHD: Neuropsychological pathways, comorbidity and symptom domains. Journal of Abnormal Child Psychology, 37(4), 551-564. doi: $10.1007 /$ s10802-008-9286-9

Wassenberg, R., Hendriksen, J. G. M., Hurks, P. P. M., Feron, F. J. M., Vles, J. S. H., \& Jolles, J. (2010). Speed of language comprehension is impaired in ADHD. Journal of Attention Disorders, 13(4), 374-385. doi: $10.1177 / 1087054708326111$

Wasserman, T., \& Wasserman, L. D. (2012). The sensitivity and specificity of neuropsychological tests in the diagnosis of attention deficit hyperactivity disorder. Applied Neuropsychology: Child, 1(2), 90-99. doi: $10.1080 / 21622965.2012 .702025$

Wechsler, D. (2003). Wechsler Intelligence Scale for Children (WISC-III) - Portuguese version (M. R. Simões, A. M. Rocha, and C. Ferreira). Lisbon: Cegoc.

Whipple, B. D., \& Nelson, J. M. (2015). Naming speed of adolescents and young adults with attention deficit hyperactivity disorder: Differences in alphanumeric versus color/object naming. Archives of Clinical Neuropsychology. doi: 10.1093/arclin/acv061

Willcutt, E. G., Betjemann, R. S., McGrath, L. M., Chhabildas, N. A., Olson, R. K., DeFries, J. C., \& Pennington, B. F. (2010). Etiology and neuropsychology of comorbidity between RD and ADHD: The case for multiple-deficit models. Cortex, 46(10), 1345-1361. doi: 10.1016/j.cortex.2010.06.009 
Willcutt, E. G., Doyle, A. E., Nigg, J. T., Faraone, S. V., \& Pennington, B. F. (2005). Validity of the executive function theory of attention-deficit/hyperactivity disorder: A meta-analytic review. Biological Psychiatry, 57(11), 1336-1346. doi: 10.1016/j.biopsych.2005.02.006

Willcutt, E. G., Pennington, B. F., Boada, R., Ogline, J. S., Tunick, R. A., Chhabildas, N. A., \& Olson, R. K. (2001). A comparison of the cognitive deficits in reading disability and attention-deficit/hyperactivity disorder. Journal of Abnormal Psychology, 110(1), 157-172. doi: 10.1037/0021-843X.110.1.157

Willcutt, E. G., Pennington, B. F., Olson, R. K., Chhabildas, N., \& Hulslander, J. (2005). Neuropsychological analyses of comorbidity between reading disability and attention deficit hyperactivity disorder: In search of the common deficit. Developmental Neuropsychology, 27(1), 35-78. doi:

$10.1207 / \mathrm{s} 15326942 \mathrm{dn} 2701 \_3$

Wisniewski, I., Wendling, A.-S., Manning, L., \& Steinhoff, B. J. (2012). Visuo-spatial memory tests in right temporal lobe epilepsy foci: Clinical validity. Epilepsy \& Behavior, 23(3), 254-260. doi:

10.1016/j.yebeh.2011.12.006

Wolf, M. (1986). Rapid alternating stimulus naming in the developmental dyslexias. Brain and Language, 27(2), 360-379. doi: 10.1016/0093-934x(86)90025-8

Ziegler, J. C., Bertrand, D., Tóth, D., Csépe, V., Reis, A., Faísca, L., . . Blomert, L. (2010). Orthographic depth and its impact on universal predictors of reading: A cross-language investigation. Psychological Science, 21(4), 551-559. doi: 10.1177/0956797610363406 
Table 1. Means and standard deviations of the four groups on measures of intellectual ability and neurocognitive functioning

\begin{tabular}{|c|c|c|c|c|c|c|c|}
\hline & \multirow{2}{*}{$\frac{\mathrm{TDC}}{\mathrm{M} \pm \mathrm{SD}}$} & \multirow{2}{*}{$\begin{array}{l}\text { DD-only } \\
\mathrm{M} \pm \mathrm{SD}\end{array}$} & \multirow{2}{*}{$\frac{\text { ADHD-only }}{\mathrm{M} \pm \mathrm{SD}}$} & \multirow{2}{*}{$\frac{\mathrm{DD}+\mathrm{ADHD}}{\mathrm{M} \pm \mathrm{SD}}$} & \multicolumn{2}{|c|}{ Main Effect $(F)$} & \multirow{2}{*}{$\begin{array}{c}\text { Interaction } \\
\text { Effect }(F) \\
\text { DD x ADHD }\end{array}$} \\
\hline & & & & & DD & ADHD & \\
\hline \multicolumn{8}{|l|}{ Intellectual Ability } \\
\hline WISC-III GAI & $106.68 \pm 10.29^{\mathrm{a}}$ & $103.53 \pm 10.30^{\mathrm{a}}$ & $101.69 \pm 7.14^{\mathrm{a}}$ & $105.53 \pm 11.34^{\mathrm{a}}$ & 0.034 & 0.632 & 3.450 \\
\hline \multicolumn{8}{|c|}{ Phonological Awareness } \\
\hline Deletion & $11.44 \pm 1.83^{\mathrm{a}}$ & $5.38 \pm 2.34^{\mathrm{b}}$ & $7.34 \pm 3.66^{\mathrm{c}}$ & $5.28 \pm 1.93^{b}$ & $66.165^{* * *}$ & $17.607 * * *$ & $16.013^{* * *}$ \\
\hline Substitution & $10.81 \pm 2.65^{\mathrm{a}}$ & $4.72 \pm 2.63^{\mathrm{b}}$ & $6.38 \pm 4.48^{\mathrm{b}}$ & $3.94 \pm 2.58^{\mathrm{b}}$ & $46.613^{* * *}$ & $17.420^{* *}$ & $8.604^{* *}$ \\
\hline Composite score & $11.13 \pm 1.81^{\mathrm{a}}$ & $5.05 \pm 2.24^{\mathrm{b}}$ & $6.86 \pm 3.84^{\mathrm{c}}$ & $4.61 \pm 2.01^{\mathrm{b}}$ & $66.753 * * *$ & $21.287 * * *$ & $14.128^{* * *}$ \\
\hline \multicolumn{8}{|l|}{ Naming Speed } \\
\hline RAN & $12.00 \pm 3.11^{\mathrm{a}}$ & $6.59 \pm 3.14^{b}$ & $6.78 \pm 3.83^{b}$ & $5.33 \pm 2.89^{b}$ & $29.170 * * *$ & $26.066^{* * *}$ & $9.729 * *$ \\
\hline RAS & $10.15 \pm 2.50^{\mathrm{a}}$ & $5.28 \pm 3.15^{b}$ & $5.56 \pm 3.78^{b}$ & $3.89 \pm 2.97^{\mathrm{b}}$ & $29.303 * * *$ & $24.479 * * *$ & $6.982 * *$ \\
\hline Composite score & $11.07 \pm 2.25^{\mathrm{a}}$ & $5.94 \pm 2.73^{b}$ & $6.17 \pm 3.42^{b}$ & $4.61 \pm 2.45^{b}$ & $39.490 * * *$ & $34.155^{* * *}$ & $11.256^{* *}$ \\
\hline \multicolumn{8}{|l|}{ Processing Speed } \\
\hline Coding & $11.44 \pm 2.51^{\mathrm{a}}$ & $9.87 \pm 2.64^{\mathrm{a}, \mathrm{b}}$ & $9.31 \pm 2.96^{b}$ & $8.47 \pm 2.62^{b}$ & $5.305 *$ & $11.419^{* * *}$ & 0.480 \\
\hline Symbol Search & $11.56 \pm 2.93^{\mathrm{a}}$ & $10.22 \pm 2.57^{\mathrm{a}, \mathrm{b}}$ & $10.68 \pm 2.27^{\mathrm{a}, \mathrm{b}}$ & $9.00 \pm 1.77^{\mathrm{b}}$ & $9.530 * *$ & $4.616^{*}$ & 0.119 \\
\hline Composite score & $11.50 \pm 2.53^{\mathrm{a}}$ & $10.05 \pm 2.28^{\mathrm{a}, \mathrm{b}}$ & $9.86 \pm 2.46^{\mathrm{b}}$ & $8.74 \pm 1.95^{b}$ & $7.884 * *$ & $10.346^{* *}$ & 0.129 \\
\hline \multicolumn{8}{|l|}{ Verbal WM } \\
\hline Arithmetic & $12.21 \pm 2.16^{\mathrm{a}}$ & $9.84 \pm 2.20^{\mathrm{b}}$ & $9.56 \pm 2.14^{b}$ & $9.24 \pm 2.39^{b}$ & $9.923^{* *}$ & $14.509 * * *$ & $5.682 *$ \\
\hline Digit Span & $9.50 \pm 1.97^{\mathrm{a}}$ & $7.72 \pm 1.55^{b}$ & $9.66 \pm 2.81^{\mathrm{a}}$ & $7.56 \pm 2.31^{b}$ & $20.254 * * *$ & 0.001 & 0.132 \\
\hline Word Learning List & $9.86 \pm 2.80^{\mathrm{a}}$ & $7.13 \pm 2.24^{\mathrm{b}, \mathrm{c}}$ & $8.19 \pm 2.52^{\mathrm{a}, \mathrm{b}}$ & $5.27 \pm 2.61^{\mathrm{c}}$ & $24.745^{* * *}$ & $9.687 * *$ & 0.026 \\
\hline Composite score & $10.52 \pm 1.44^{\mathrm{a}}$ & $8.41 \pm 1.39^{\mathrm{b}}$ & $9.14 \pm 1.82^{\mathrm{b}}$ & $7.92 \pm 1.82^{\mathrm{b}}$ & $29.360 * * *$ & $9.380 * *$ & 2.110 \\
\hline
\end{tabular}




\section{Visuospatial STM}

Rey Complex Figure

$9.40 \pm 3.23^{\mathrm{a}}$
$10.59 \pm 2.9^{\mathrm{a}}$
$10.00 \pm 2.23^{\mathrm{a}}$

$8.47 \pm 3.20^{\mathrm{a}}$

$$
\begin{aligned}
& 7.28 \pm 3.09^{\mathrm{a}} \\
& 8.03 \pm 3.06^{\mathrm{b}} \\
& 7.66 \pm 2.54^{\mathrm{b}}
\end{aligned}
$$$$
10.09 \pm 2.50^{\mathrm{a}}
$$

$$
8.94 \pm 3.96^{\mathrm{a}}
$$$$
0.330
$$

1.680

4.184*

Composite score

$8.80 \pm 2.73^{\mathrm{a}, \mathrm{b}}$

$10.45 \pm 1.63^{\mathrm{a}, \mathrm{b}}$

2.475

3.209

$5.727 *$

\section{Shifting}

$$
\text { Trail-B }{ }^{+}
$$

$0.60 \pm 0.77^{\mathrm{a}}$

$-0.20 \pm 0.79^{b}$

$-0.14 \pm 1.14^{\mathrm{b}}$

$-0.50 \pm 0.94^{b}$

\begin{tabular}{|c|c|c|c|c|c|c|c|}
\hline Semantic & $11.86 \pm 3.19^{\mathrm{a}}$ & $9.06 \pm 3.16^{b}$ & $9.28 \pm 3.43^{b}$ & $8.67 \pm 2.99^{b}$ & $7.614^{* *}$ & $5.787^{*}$ & 3.117 \\
\hline Phonemic & $11.26 \pm 3.50^{\mathrm{a}}$ & $9.63 \pm 2.74^{\mathrm{a}, \mathrm{b}}$ & $8.66 \pm 3.21^{b}$ & $9.00 \pm 3.20^{\mathrm{a}, \mathrm{b}}$ & 1.120 & $7.005^{*}$ & 2.631 \\
\hline Composite score & $11.56 \pm 2.80^{\mathrm{a}}$ & $9.34 \pm 2.52^{\mathrm{b}}$ & $8.97 \pm 2.86^{b}$ & $8.83 \pm 2.83^{b}$ & $4.968^{*}$ & $8.641^{* *}$ & 3.890 \\
\hline
\end{tabular}

$10.817^{* * *}$

$8.782 * *$

1.654

\section{Verbal Fluency}

Note. ${ }^{*} p<.05,{ }^{* *} p<.01,{ }^{* * *} p<.001$. All variables in age-scaled scores $(M=10, S D=3)$, except GAI scores (standard IQ units with $M=100$ and $\left.S D=15\right)$ and Trail-B (standardized residual score). Means with different superscripts $\left({ }^{a}, \mathrm{~b}, \mathrm{c}\right)$ are significantly different at the $p=.05$ level after Bonferroni adjustment for multiple comparisons. ${ }^{+}$

Standardized residual score. TDC $=$ typically developing children. DD = children with Developmental Dyslexia. ADHD = children with Attention-Deficit/Hyperactivity

Disorder. DD+ADHD = comorbid group (children with DD and ADHD). WISC-III = Wechsler Intelligence Scale for Children $($ Third Edition $)$. GAI $=$ General Ability Index.

RAN $=$ Rapid Automatized Naming. RAS $=$ Rapid Alternating Stimulus. WM = working memory. STM = short-term memory. 
Table 2. Effect sizes (Cohen's $d$ ) comparing groups across composite scores of neurocognitive domains

\begin{tabular}{lcccccc}
\hline & $\begin{array}{c}\text { TDC vs. DD- } \\
\text { only }\end{array}$ & $\begin{array}{c}\text { TDC vs. } \\
\text { ADHD-only }\end{array}$ & $\begin{array}{c}\text { TDC vs. } \\
\text { DD+ADHD }\end{array}$ & $\begin{array}{c}\text { DD-only vs. } \\
\text { ADHD-only }\end{array}$ & $\begin{array}{c}\text { DD-only vs. } \\
\text { DD+ADHD }\end{array}$ & $\begin{array}{c}\text { ADHD-only } \\
\text { vs. DD+ADHD }\end{array}$ \\
\hline $\begin{array}{l}\text { Phonological } \\
\text { Awareness }\end{array}$ & $\mathbf{2 . 9 8}$ & $\mathbf{1 . 4 2}$ & $\mathbf{3 . 4 0}$ & -0.57 & 0.20 & 0.73 \\
Naming Speed & $\mathbf{2 . 0 5}$ & $\mathbf{1 . 6 9}$ & $\mathbf{2 . 7 4}$ & -0.07 & 0.51 & 0.52 \\
Processing Speed & 0.60 & 0.66 & $\mathbf{1 . 2 2}$ & 0.08 & 0.61 & 0.50 \\
Verbal WM & $\mathbf{1 . 5 0}$ & $\mathbf{0 . 8 4}$ & $\mathbf{1 . 5 8}$ & -0.44 & 0.30 & -0.57 \\
Visuospatial STM & 0.48 & $\mathbf{0 . 9 8}$ & 0.31 & 0.43 & -0.11 & -0.51 \\
Shifting & $\mathbf{1 . 0 3}$ & 0.76 & $\mathbf{1 . 2 8}$ & -0.06 & 0.34 & 0.34 \\
Verbal Fluency & $\mathbf{0 . 8 3}$ & $\mathbf{0 . 9 2}$ & $\mathbf{0 . 9 6}$ & 0.14 & 0.19 & 0.04
\end{tabular}

Note $. \mathrm{TDC}=$ typically developing children. $\mathrm{DD}=$ children with Developmental Dyslexia. $\mathrm{ADHD}=$ children with Attention-Deficit/Hyperactivity Disorder. DD+ADHD = comorbid group (children with DD and ADHD).

$\mathrm{WM}=$ Working Memory. STM $=$ short-term memory. Bold numbers represent effect sizes $>0.80$ or $<-0.80$. 
Table 3. Binary logistic regression analysis and receiver operating characteristics curve analysis

\begin{tabular}{|c|c|c|c|c|c|c|c|c|c|}
\hline & \multicolumn{4}{|c|}{ TDC vs. DD-only } & \multicolumn{4}{|c|}{ TDC vs. ADHD-only } & \multirow[t]{2}{*}{$\begin{array}{l}\text { DD-only vs. } \\
\text { ADHD-only }\end{array}$} \\
\hline & \multicolumn{3}{|c|}{ Binary Logistic Regression } & \multirow[b]{2}{*}{ AUC } & \multicolumn{3}{|c|}{ Binary Logistic Regression } & \multirow[b]{2}{*}{ AUC } & \\
\hline & Sen / Sp & $\mathrm{B}$ & OR & & $\mathrm{Sen} / \mathrm{Sp}$ & $\mathrm{B}$ & OR & & AUC \\
\hline Phonological Awareness & $93.8 / 94.1$ & & & & $75.0 / 88.2$ & & & & \\
\hline Deletion & & $-0.712 *$ & 0.491 & .966 & & $-0.406^{*}$ & 0.666 & .819 & .665 \\
\hline Substitution & & -0.507 & 0.602 & .950 & & -0.123 & 0.884 & .804 & .577 \\
\hline Naming Speed & $81.3 / 88.2$ & & & & $75.0 / 88.2$ & & & & \\
\hline RAN & & $-0.369 * *$ & 0.691 & .881 & & $-0.277^{*}$ & 0.758 & .844 & .506 \\
\hline RAS & & $-0.432 * *$ & 0.649 & .877 & & $-0.260^{*}$ & 0.771 & .825 & .524 \\
\hline Processing Speed & $65.6 / 61.7$ & & & & $58.1 / 79.4$ & & & & \\
\hline Coding & & -0.203 & 0.816 & .677 & & $-0.310^{*}$ & 0.733 & .688 & .579 \\
\hline Symbol Search & & -0.060 & 0.941 & .625 & & 0.037 & 1.030 & .583 & .543 \\
\hline Verbal WM & $78.2 / 82.4$ & & & & $75.0 / 79.4$ & & & & \\
\hline Arithmetic & & $-0.327^{*}$ & 0.720 & .788 & & $-0.553 * * *$ & 0.574 & .810 & .501 \\
\hline Digit Span & & $-0.809^{*}$ & 0.445 & .783 & & 0.171 & 1.186 & .540 & .692 \\
\hline Word Learning List & & $-0.448 * *$ & 0.638 & .781 & & -0.131 & 0.876 & .690 & .621 \\
\hline Visuospatial STM & $4.3 / 100$ & & & & $62.5 / 61.8$ & & & & \\
\hline Rey Complex Figure & & -0.021 & 0.978 & .522 & & -0.186 & 0.830 & .678 & .670 \\
\hline Corsi Blocks & & -0.067 & 0.934 & .552 & & $-0.274 * *$ & 0.760 & .744 & .696 \\
\hline Shifting & $68.8 / 79.4$ & & & & $56.3 / 79.4$ & & & & \\
\hline Trail-B & & $-1.353 * *$ & 0.258 & .802 & & -0.869 & 0.419 & .727 & .520 \\
\hline Verbal Fluency & $59.4 / 58.8$ & & & & $75.0 / 61.8$ & & & & \\
\hline
\end{tabular}


Note. ${ }^{*} p<.05,{ }^{* *} p<.01,{ }^{* * *} p<.001$. TDC = typically developing children. DD = children with Developmental Dyslexia. ADHD = children with Attention-Deficit/Hyperactivity

Disorder. RAN $=$ Rapid Automatized Naming. RAS $=$ Rapid Alternating Stimulus. $\mathrm{WM}=$ Working Memory. STM $=$ short-term memory. Sen $=$ sensitivity. Sp $=$ specificity. OR $=$ odds ratio. $\mathrm{AUC}=$ area under the curve from the receiver operating characteristics curve analysis. 